\title{
Surgical outcome of intradural extramedullary spinal cord tumors - Our experience at a tertiary health care center
}

\author{
Corresponding author \\ Gyanendra Joshi, MS \\ Email: gyanendrajoshi1@gmail.com
}

Gyanendra Joshi, MS; Binod Bijukachhe, MS; Javed Ahmad Khan, MS

Spine services, Department of Orthopedics, Grande International Hospital, Kathmandu, Nepal

Received 13 Aug 2019

Accepted 2 Nov 2019

\begin{abstract}
Introduction:

To report the treatment results of 19 patients who underwent excision of intradural extramedullary (IDEM) spinal tumors.
\end{abstract}

\section{Materials \& Methods:}

This is a retrospective study. Patients' records were retrieved from the electronic database of Grande International Hospital. There were 19 IDEM spinal tumors excised over a period of 6 years between January 2013 and August 2019 by a single surgeon. There were 11 (57.9\%) males and 8 (42.1\%) females with an average age of $48.37 \pm 21.87$ years (range, $5-79$ years). The mean postoperative follow-up period was $12.87 \pm 14.88$ months (range, 15 days - 60 months). The histopathological findings, locations of the tumors, and clinical results were analyzed. Neurological findings were evaluated using ASIA grading system and pain was evaluated using VAS score.

\section{Results:}

Histopathologically the tumors were: 8 meningioma (42.1\%), 4 schwannoma (21.1\%), 4 neurofibroma (21.1\%), 1 dermoid cyst (5.3\%), 1 lipoma (5.3\%), and 1 myxopapillary ependymoma (5.3\%). Tumor locations were: dorsal in 10 (52.6\%), lumbar in 5 (26.3\%), lumbosacral in 2 (10.5\%), dorsolumbar in 1 (5.3\%), and cervical in $1(5.3 \%)$ patient. Neurologic status of 7 patients was normal and 12 had neurologic involvement with 3 patients having Cauda Equina Syndrome (CES) preoperatively. At the final follow-up, 3-grade, 2-grade and 1-grade improvement in ASIA score was observed in 1, 6 and 1 cases, respectively. There was no change in the ASIA grade in 1 case. All 3 cases of CES achieved full neural recovery. Preoperative VAS score was $9.21 \pm 1.08$ and improved significantly to $0.74 \pm 1.62$ after surgery. Neurological improvement was seen in $91.67 \%$ with complete recovery in $75 \%$ of the cases and not a single case deteriorated neurologically post-surgery.

\section{Conclusion:}

Most intradural-extramedullary spinal cord tumors are mostly benign and good clinical results can be obtained when adequately treated with surgery.

Key words: IDEM spinal tumors, Cauda Equina Syndrome 


\section{Introduction}

Primary spinal cord tumors accounts for $2-4 \%$ of all primary central nervous system neoplasms which includes extradural, intradural-extramedullary (IDEM), and intramedullary tumors ${ }^{1}$. IDEM tumors account for $40-45 \%$ of all tumors found in the spinal canal ${ }^{2}$ when complete, no further therapy is required. Astrocytomas, by contrast, infiltrate the myelon, and therefore surgery is frequently incomplete. Intradural extramedullary tumors are mostly benign (WHO grade 1 . Most common IDEM tumors are meningioma, schwannoma, or neurofibroma having similar incidence ${ }^{3,4}$. Lipomas, metastases, paragangliomas, sarcomas, spinal nerve sheath myxomas, and vascular tumors are other IDEM tumors 5 .

Most of these tumors are benign and surgery may result in a cure of these conditions ${ }^{2}$. Many studies have shown gross total resection results in significant neurologic improvement regardless of the level of preoperative neurologic dysfunction and with minimal morbidity ${ }^{6-8}$. However, IDEMs like en plaque meningioma, diffuse leptomeningeal glioneuronal tumor (DLGNT) and those tumors firmly adhered to the underlying spinal roots and rootlets and those arising from the ventral cord are almost impossible to grossly resect without causing neurological damages. In such tumors, residue is deliberately left to preserve the neurological function.

Diagnostic tools like CT and MRI, and the advancement of surgical instrumentation and techniques have improved the surgical outcome in IDEM tumors. This study is conducted to evaluate the surgical outcome of 19 patients who underwent a total excision of the IDEM tumor.

\section{Materials and methods}

This is a retrospective study. Patients' records were retrieved from the electronic database of Grande International Hospital. There were 19 IDEM spinal tumors excised over a period of 6 years between January 2013 and August 2019 by a single surgeon. The histopathological findings, locations of the tumors, and clinical results were analyzed. Neurological findings were evaluated using ASIA (American Spinal Injury Association) grading system and pain was evaluated using VAS (Visual Analog Score) score.
Table 1. ASIA Grade

\begin{tabular}{|c|l|l|}
\hline Grade & Extension & \multicolumn{1}{c|}{ Neurologic Evaluation } \\
\hline A & Complete & $\begin{array}{l}\text { No motor or sensory function } \\
\text { preserved in the } \\
\text { S4-5 segments }\end{array}$ \\
\hline B & Incomplete & $\begin{array}{l}\text { Sensory, but no motor func- } \\
\text { tion preserved below the } \\
\text { affected level and extending } \\
\text { through the S4-5 segments }\end{array}$ \\
\hline C & Incomplete & $\begin{array}{l}\text { Motor function preserved } \\
\text { below the affected level, and } \\
\text { the majority of key muscles } \\
\text { below the affected level are }< \\
\text { grade 3/5 }\end{array}$ \\
\hline D & Incomplete & $\begin{array}{l}\text { Motor function preserved } \\
\text { below the affected level, \& } \\
\text { the majority of key muscles } \\
\text { below the affected level are } \geq \\
\text { grade 3/5 }\end{array}$ \\
\hline E & Normal & $\begin{array}{l}\text { Motor \& sensory function } \\
\text { normal }\end{array}$ \\
\hline
\end{tabular}

Clinical outcome was assessed at last followup. Data analysis was done with MS Excel 2010, and SPSS 20. Values for numerical variables are expressed as mean $\pm S D$ and for categorical variables as frequency (\%).

\section{Results}

There were $11(57.9 \%)$ males and $8(42.1 \%)$ females with an average age of 48.37 years (range, 5-79 years). The mean postoperative follow-up period was 12.87 months. All the patients were operated by performing a posterior midline skin incision, laminectomy/hemilaminectomy, durotomy and excision of tumor completely or partially, depending upon adherence of the tumor to the cord, root/rootlet or location of the tumor to the cord (anteriorly or posteriorly). The most common site of lesions on MRI in our study was dorsal in $10(52.6 \%)$, lumbar in 5 (26.3\%), lumbosacral in $2(10.5 \%)$, dorsolumbar in $1(5.3 \%)$, and cervical in $1(5.3 \%)$ patient. The histopathological results were as follows: $8(42.1 \%)$ cases of meningioma,

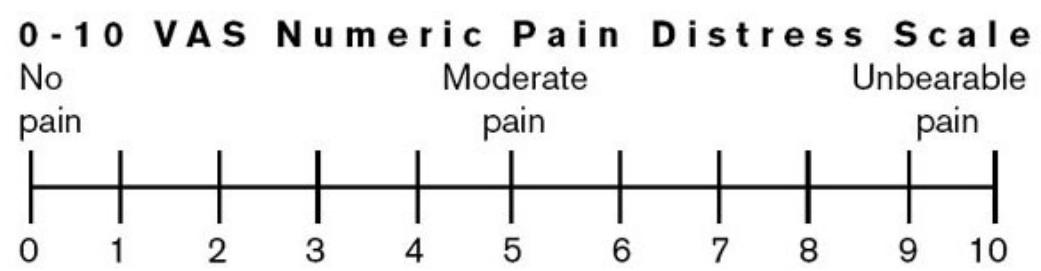

Figure VAS Score 
Table 2. Demographic profile and outcomes

\begin{tabular}{|c|c|c|c|c|c|c|c|c|c|}
\hline \multirow{2}{*}{ S.N } & \multirow{2}{*}{ Sex } & \multirow{2}{*}{$\begin{array}{l}\text { Age } \\
\text { (yrs) }\end{array}$} & \multirow{2}{*}{ Level } & \multirow{2}{*}{ Histopatholgy } & \multirow{2}{*}{$\begin{array}{c}F / U \\
\text { (months) }\end{array}$} & \multicolumn{2}{|c|}{ ASIA } & \multicolumn{2}{|c|}{ Pain } \\
\hline & & & & & & Pre-op & Post-op & Pre-op & Post-op \\
\hline 1 & $\mathrm{M}$ & 25 & C4-5 & Neurofibroma & 3 & B & B & 10 & 5 \\
\hline 2 & $\mathrm{~F}$ & 76 & D2-3 & Meningioma & 1 & B & C & 8 & 0 \\
\hline 3 & $\mathrm{M}$ & 30 & L3-5 & Lipoma & 0.5 & CES & $\mathrm{E}$ & 10 & 5 \\
\hline 4 & $\mathrm{~F}$ & 18 & L1-3 & Schwannoma & 1.5 & $\mathrm{E}$ & $\mathrm{E}$ & 10 & 0 \\
\hline 5 & $\mathrm{M}$ & 48 & D12-L1 & Schwannoma & 3 & $E$ & $E$ & 10 & 0 \\
\hline 6 & $\mathrm{M}$ & 5 & $\mathrm{~L} 2-3$ & Dermoid Cyst & 3 & $E$ & $E$ & 10 & 0 \\
\hline 7 & $\mathrm{M}$ & 35 & L2-3 & Schwannoma & 4.5 & $E$ & $E$ & 8 & 0 \\
\hline 8 & $\mathrm{M}$ & 68 & D10-11 & Meningioma & 9 & $\mathrm{E}$ & $\mathrm{E}$ & 8 & 0 \\
\hline 9 & $\mathrm{~F}$ & 54 & L5-S1 & Myxopapillary Ependymoma & 9 & CES & $E$ & 10 & 0 \\
\hline 10 & $\mathrm{~F}$ & 79 & D7-8 & Meningioma & 12 & C & $\mathrm{E}$ & 10 & 0 \\
\hline 11 & $M$ & 49 & D7-8 & Schwannoma & 12 & $C$ & $E$ & 10 & 0 \\
\hline 12 & $\mathrm{~F}$ & 34 & D6 & Meningioma & 12 & $E$ & $E$ & 8 & 0 \\
\hline 13 & $\mathrm{~F}$ & 30 & D7 & Meningioma & 12 & C & $E$ & 8 & 0 \\
\hline 14 & $\mathrm{~F}$ & 7 & D3-4 & Meningioma & 14 & $\mathrm{C}$ & $E$ & 10 & 0 \\
\hline 15 & $\mathrm{M}$ & 65 & D9-10 & Neurofibroma & 26 & C & $\mathrm{E}$ & 10 & 0 \\
\hline 16 & $\mathrm{~F}$ & 76 & D2 & Meningioma & 36 & $B$ & $E$ & 8 & 0 \\
\hline 17 & $\mathrm{M}$ & 61 & L5-S1 & Neurofibroma & 60 & CES & $E$ & 10 & 0 \\
\hline 18 & $\mathrm{M}$ & 52 & D5-6 & Neurofibroma & 24 & $B$ & $\mathrm{D}$ & 10 & 2 \\
\hline 19 & $\mathrm{M}$ & 38 & L2-3 & Meningioma & 2 & $\mathrm{E}$ & $E$ & 7 & 2 \\
\hline
\end{tabular}

Table 3: Demographic data of 19 patients with IDEM tumors*

\begin{tabular}{|c|c|c|}
\hline Characteristics & Number & Percentage \\
\hline \multicolumn{3}{|l|}{ Gender } \\
\hline Female & 8 & 42.1 \\
\hline Male & 11 & 57.9 \\
\hline Mean Age in yrs \pm SD (Range) & $48.37 \pm 21.87$ (5-79yrs) & \\
\hline Mean follow up period months $\pm S D$ (Range) & $12.87 \pm 14.88$ ( 15 days -60 months) & \\
\hline \multicolumn{3}{|l|}{ Region } \\
\hline Cervical & 1 & 5.3 \\
\hline Dorsal & 10 & 52.6 \\
\hline Dorsolumbar & 1 & 5.3 \\
\hline Lumbar & 5 & 26.3 \\
\hline Lumbosacral & 2 & 10.5 \\
\hline \multicolumn{3}{|l|}{ Gait } \\
\hline Ataxic & 4 & 21.1 \\
\hline Normal & 8 & 42.1 \\
\hline Spastic & 7 & 36.8 \\
\hline \multicolumn{3}{|l|}{ Diagnosis } \\
\hline Dermoid Cyst & 1 & 5.3 \\
\hline Lipoma & 1 & 5.3 \\
\hline Meningioma & 8 & 42.1 \\
\hline Myxopapillary Ependymoma & 1 & 5.3 \\
\hline Neurofibroma & 4 & 21.1 \\
\hline Schwannoma & 4 & 21.1 \\
\hline \multicolumn{3}{|l|}{ Location } \\
\hline IDEM & 17 & 89.5 \\
\hline IDEM + ED & 2 & 10.5 \\
\hline
\end{tabular}

* Except where otherwise indicated, the values are expressed as number (\%) 
$4(21.1 \%)$ cases of schwannoma, $4(21.1 \%)$ cases of neurofibroma, $1(5.3 \%)$ case of dermoid cyst, $1(5.3 \%)$ case of lipoma, and $1(5.3 \%)$ case of myxopapillary ependymoma. Meningioma was more common in females and nerve sheath tumors were more common in males. Neurologic status of 7 patients was normal and 12 had neurologic involvement with 3 patients exhibiting Cauda Equina Syndrome (CES). The preoperative ASIA grade was $B$ in 4 cases, $C$ in 5 cases, $E$ in 7 cases and CES in 3 cases. At the final follow-up, 3-grades, 2-grade and 1-grade improvement in ASIA score was observed in $1(8.33 \%), 6(50 \%)$ and 1 case $(8.33 \%)$ respectively. There was no change in the ASIA grade (B) in 1 case (8.33\%). All 3 cases of CES achieved full neural recovery. Preoperative VAS score was $9.21+/-1.08$ and improved significantly to $0.74 \pm 1.62$ after surgery. Neurological improvement was seen in $91.67 \%$ with complete recovery in $75 \%$ of the cases and not a single case deteriorated neurologically post-surgery. A case of neurofibroma died after 3 months post- surgery due to chest infection.

Table 4. Functional Neurological Outcome (ASIA Grade)

\begin{tabular}{|c|c|c|c|c|c|c|c|}
\hline \multirow{2}{*}{$\begin{array}{c}\text { Pre-Op ASIA } \\
\text { Grade }\end{array}$} & \multicolumn{6}{|c|}{ Post-op ASIA Grade } \\
\hline & A & B & C & D & E & Total \\
\hline A & 0 & 0 & & & & & 0 \\
\hline B & 4 & & 1 & 1 & 1 & 1 & 4 \\
\hline C & 5 & & & & & 5 & 5 \\
\hline D & 0 & & & & & & 0 \\
\hline E & 7 & & & & & 7 & 7 \\
\hline CES & 3 & & & & & 3 & 3 \\
\hline Total & 19 & 0 & 1 & 1 & 1 & 16 & 19 \\
\hline
\end{tabular}

Table 5. Comparsion of VAS score with other studies

\begin{tabular}{|l|c|c|}
\hline \multicolumn{1}{|c|}{ Study } & $\begin{array}{c}\text { VAS score pre- } \\
\text { operatively }\end{array}$ & $\begin{array}{c}\text { VAS score post- } \\
\text { operatively }\end{array}$ \\
\hline Kankane et al. $^{9}$ & $7.56 \pm 0.72$ & $1.30 \pm 0.47$ \\
\hline Ahn et al. ${ }^{10}$ & $8.0 \pm 1.2$ & $1.2 \pm 0.8$ \\
\hline Our study & $9.21 \pm 1.08$ & $0.74 \pm 1.62$ \\
\hline
\end{tabular}

\section{Discussion}

In 1887, Dr. Horsley resected a spinal cord tumor of dorsal spine in a patient presenting with spasticity and paraplegia ${ }^{11}$. After surgery the patient made marked improvement and regained the ability
Table 6. Male: Female ratios of different tumors

\begin{tabular}{|l|c|c|c|c|}
\hline Type of tumor & $\begin{array}{c}\text { Male } \\
(\mathbf{n = 1 1})\end{array}$ & $\begin{array}{c}\text { Fe- } \\
\text { male } \\
(\mathbf{n}=\mathbf{8})\end{array}$ & $\begin{array}{c}\text { Total } \\
(\mathbf{n = 1 9})\end{array}$ & $\begin{array}{c}\text { M:F } \\
\text { ratio }\end{array}$ \\
\hline Meningioma & 2 & 6 & 8 & $1: 3$ \\
\hline Neurofibroma & 4 & & 4 & $100 \%$ \\
\hline Schwannoma & 3 & 1 & 4 & $3: 1$ \\
\hline Lipoma & 1 & & 1 & $1: 0$ \\
\hline $\begin{array}{l}\text { Myxopapillary } \\
\text { Ependymoma }\end{array}$ & & 1 & 1 & $0: 1$ \\
\hline Dermoid Cyst & 1 & & 1 & $1: 0$ \\
\hline
\end{tabular}

to walk and survived for another 20 years. Advancement in neuroimaging (MRI with contrast enhancement), intraoperative neurophysiological monitoring and microsurgical techniques have brought drastic improvement in surgical outcome of spinal cord tumors patient. Neurophysiological monitoring now-a-days have become a standard in for all spinal surgeries in advanced centers. Tasks during surgery - cord manipulations, retraction, heat generated from high speed drills during laminectomy can all lead to varying degrees of cord injury. Early detection of cord compromise via monitoring of SSEP, MEP, D-waves, $\mathrm{H}$-reflex during spinal surgeries alerts the operating surgeon early enough to take remedial action to preventing cord damage and neurological deficit.

Most IDEM tumors are benign, well circumscribed and show clear demarcations to spinal cord tissue, creating a possibility of total excision of the tumor. However, IDEMs like en plaque meningioma, diffuse leptomeningeal glioneuronal tumor (DLGNT) and those tumors firmly adhered to the underlying spinal roots and rootlets and those arising from the ventral cord are almost impossible to grossly resect without causing neurological damages. In such tumors, residue is deliberately left to preserve the neurological function.

Early diagnosis and treatment, preoperative neurological status, duration of cord compression before surgery, the extent of the excision, and histopathological findings are important factors in determining the surgical outcome of these patients ${ }^{12}$. IDEM tumors have incidence of 3 out of $10,00,000$ people and account for $40-45 \%$ of primary spinal tumors ${ }^{13}$. More than $50 \%$ of these tumors are found in the thoracic spine ${ }^{14}$. Many articles have cited schwannoma $(30 \%-50 \%)$ as the 
most common and meningioma (20\%-25\%) as the second most common primary IDEM spinal tumor. However a review of 5564 primary intradural spinal tumors in the Surveillance, Epidemiology, and End Results (SEER) database in 2014 showed meningioma as the most common (1709 cases, $30.7 \%$ ), while schwannoma and other nerve sheath tumors were less common $(15.5 \%)^{15-17}$. In our series, mean age was 48.37 , thoracic spine was the commonest location and meningiomas were the commonest type of tumor encountered followed by schwannoma and neurofibroma with equal incidence. We did not have any metastatic case to the spinal cord.

The demographics in our study are similar to those in previous studies ${ }^{18,19}$. We found that schwannomas affected younger male patients while neurofibroma affects older patients, and meningiomas tend to occur in women and older patients.

Many studies of IDEM tumors reported marked improvement of pain after surgery ${ }^{8,20}$. Ahn et al. revealed that the mean VAS score was reduced in all cases from 8 before surgery to 1.2 after surgery, whereas Ahsan et al. reported a reduction of the mean VAS score from 7.67 preoperatively to 1.14 postoperatively ${ }^{8,21}$. Mean VAS score was reduced from 9.21 preoperative to 0.74 postoperative in our study, which is comparable to previous studies.

Neurological improvement following surgery is impressive in many studies. Konovalov et al. reported that $50 \%$ of patients moved to higher functional class of McCormick scale after laminectomy and resection of tumor ${ }^{22}$. Similarly, $\mathrm{Gu}$ et al. revealed that $93 \%$ of their patients had improved Frankel grade, whereas $7 \%$ of patients had no change in their grade after surgery ${ }^{23}$. Ahsan et al. and Ahn et al. reported that the mean Nurick's grade had improved from 3 preoperatively to 1 postoperatively ${ }^{12,8}$. Like previous studies, in our series there was improvement in neurology in $91.67 \%$ of patients with complete recovery in $75 \%$ of the cases and not a single case deteriorated neurologically post-surgery. This is consistent with results from other studies that showed good outcomes in $87 \%$ of patients ${ }^{7,24}$.

Klekamp et al. reported that the overall outcome could be favorable when the interval from the diagnosis prior to the development of severe neurological deficits to surgery was short ${ }^{25}$ I was firmly involved in the surgery of spinal lesions, and achieved surgical removal of spinal arteriovenous malformations (AVMs. MRI is the investigation of choice and helps in assessing the size, shape, location and relations of the tumor with the duramater and spinal cord ${ }^{26}$. Surgical outcome and postoperative morbidity can be improved by the use of intraoperative neurophysiological monitoring (IONM) ${ }^{16,27}$. Because of unavailability, we have not used IONM. Intraoperative C-arm and USG are very useful to localize tumor ${ }^{28,29}$, however we don't have any experience with intra-operative ultrasound.

Laminectomies done for tumor excision may cause spinal instability and deformity if facets, its capsules and intertransverse ligaments are damaged. Hemilaminectomy can be an ideal option for some IDEM tumor resection $30,31,22,23$. Most IDEM neoplasms are meningiomas or nerve sheath tumors, the latter of consisting of both schwannomas and neuro?bromas. Microscopic total excision while preserving and improving neurologic function is the usual goal of surgery ${ }^{18,22,31}$. Some neurosurgeons are also using intraoperative USG to localize tumor ${ }^{21,32}$. The operative approach is planned based on clinical, neurologic and radiological evaluation. Approaches are based on location, size and extent of tumors and other parameters. Radiosurgery is another treatment option, especially for recurrent and residual lesions or when surgery is contraindicated. Recurrence rate for meningiomas is about $3-7 \%{ }^{32,33}$ and for nerve sheath spinal tumors was reported to be 10 to $28 \%^{6,32,33}$ after 5 to 15 years respectively.

The limitation of this study was small sample size, retrospective in nature, done without the use of operating microscope or magnifying loupe and neurophysiological monitoring and loss of long term follow-up of patients. Clinical features of patients were not included in the study.

\section{Conclusion}

Most IDEM tumors tend to be histopathologically benign, and have excellent outcome when adequately treated with surgery. Although, we obtained good surgical results after tumor excision without using neuromonitoring, it is always advised to use neurophysiological monitoring, whenever and wherever available to ensure better treatment outcome. 


\section{References}

1. Chamberlain MC, Tredway TL. Adult primary intradural spinal cord tumors: A review. Curr Neurol Neurosci Rep. 2011;11(3):320-8.

2. Aghayev K, Vrionis F, C Chamberlain M. Adult Intradural Primary Spinal Cord Tumors. J Natl Compr Cancer Netw JNCCN. 2011;9:434-47.

3. Engelhard $\mathrm{HH}$, Villano JL, Porter $\mathrm{KR}$, et al. Clinical presentation, histology, and treatment in 430 patients with primary tumors of the spinal cord, spinal meninges, or cauda equina. J Neurosurg Spine. 2010;13(1):67-77.

4. Klekamp J, Samii M. Surgery of spinal tumors: Mit 105 Tabellen. Berlin: Springer; 2007.

5. Abul-Kasim K, Thurnher MM, McKeever P, Sundgren PC. Intradural spinal tumors: Current classification and MRI features. Neuroradiology. 2008;50(4):301-14.

6. Albanese V, Platania N. Spinal intradural extramedullary tumors: Personal experience. J Neurosurg Sci. 2002;46:18-24.

7. RiadH, KnafoS, SegnarbieuxF, Lonjon N. Spinal meningiomas:Surgicaloutcomeand literature review.Neurochirurgie.2013;59(1):30-4.

8. Ahn DK, Park HS, Choi DJ, Kim KS, Kim TW, Park SY. The surgical treatment for spinal intradural extramedullary tumors. Clin Orthop Surg. 2009;1(3):165-72.

9. Kankane VK, Sharma V, Gupta N. Surgical outcome of spinal intradural extramedullary tumors: A single-center prospective study of 92 cases-Assessment using Nurick's grade and visual analog scale. J Spinal Surg. 2018;5(2):63-8.

10. Ahn D-K, Park H-S, Choi D-J, Kim K-S, Kim T-W, Park S-Y. The surgical treatment for spinal intradural extramedullary tumors. Clin Orthop Surg. 2009;1(3):165-72.

11. Gowers WR, Horsley V. A case of tumour of the spinal cord. Removal; Recovery. MedicoChir Trans. 1888;71:377-430.

12. Ahsan MK, Awwal MA, Khan SI, Haque MH, Zaman N. Intradural extramedullary spinal cord tumours: A retrospective study of surgical outcomes. Bangabandhu Sheikh Mujib Med Univ J. 2016;9(1):11-9.
13. Helseth A, Mørk SJ. Primary intraspinal neoplasms in Norway, 1955 to 1986. A population-based survey of 467 patients. J Neurosurg. 1989;71(6):842-5.

14. Nittner K. Spinal meningiomas, neurinomas and neurofibromas, and hourglass tumours. In: Handbook of Clinical Neurology. Vinken $\mathrm{PH}$, Bruyn GW (Eds): Elsevier, New York; 1976:177.

15. Ruggeri AG, Fazzolari B, Colistra D, Cappelletti M, Marotta N, Delfini R. Calcified spinal meningiomas. World Neurosurg. 2017;102:406-12.

16. Bydon M, Gokaslan ZL. Spinal meningioma resection. World Neurosurg. 2015;83(6):1032-3.

17. Westwick HJ, Shamji MF. Effects of sex on the incidence and prognosis of spinal meningiomas: A Surveillance, Epidemiology, and End Results study. J Neurosurg Spine. 2015;23(3):368-73.

18. Hufana V, Tan JSH, Tan KK. Microsurgical treatment for spinal tumours. Singapore Med J. 2005;46(2):74-7.

19. Prevedello DM-S, Koerbel A, Tatsui CE, et al. Prognostic factors in the treatment of the intradural extramedullary tumors: A study of 44 cases. Arq Neuropsiquiatr. 2003;61(2A):241-7.

20. Nzokou A, Weil AG, Shedid D. Minimally invasive removal of thoracic and lumbar spinal tumors using a nonexpandable tubular retractor: Clinical article. J Neurosurg Spine.2013; 19(6):708-15.

21. Ahsan MK, Sakeb N, Ali MY, et al. Surgical outcome of intradural spinal tumors. Mymensingh Med J. 2016;25(3):514-22.

22. Konovalov NA, Shevelev IN, Nazarenko AG, Asiutin DS, Korolishin VA, Timonin SI et al. The use of minimally invasive approaches to resect intradural extramedullary spinal cord tumors. Zh Vopr Neirokhir Im N N Burdenko. $2014 ; 78(6): 24-36$.

23. Gu R, Liu J-B, Xia P, Li C, Liu G-Y, Wang $\mathrm{J}-\mathrm{C}$. Evaluation of hemilaminectomy use in microsurgical resection of intradural extramedullary tumors. Oncol Lett. 2014;7(5):1669-72. 
24. Viereck MJ, Ghobrial GM, Beygi S, Harrop JS. Improved patient quality of life following intradural extramedullary spinal tumor resection. J Neurosurg.2016; 25(5):640-5

25. Klekamp J, Samii M. Surgery of spinal tumors. Springer Science \& Business Media; 2007.

26. Harry N. The Spine. 4th ed. Philadelphia: WB Saunders Co; 1998.

27. Korn A, Halevi D, Lidar Z, Biron T, Ekstein $P$, Constantini $S$. Intraoperative neurophysiological monitoring during resection of intradural extramedullary spinal cord tumors: Experience with 100 cases. Acta Neurochir. 2014;157(5):819-30.

28. Zhou H, Miller D, Schulte DM, et al. Intraoperative ultrasound assistance in treatment of intradural spinal tumours. Clin Neurol Neurosurg. 2011;113(7):531-7.
29. Prada F, Vetrano IG, Filippini A, et al. Intraoperative ultrasound in spinal tumor surgery. J Ultrasound. 2014;17(3):195-202.

30. Sim J-E, Noh S-J, Song Y-J, Kim H-D. Removal of intradural-extramedullary spinal cord tumors with unilateral limited laminectomy. J Korean Neurosurg Soc. 2008;43(5):232-6.

31. Sun C, Meng X, Xie S, Yu Y, Yang H, Wu B. Unilateral hemilaminectomy for patients with intradural extramedullary tumors. J Zhejiang Univ Sci B. 2011; 12(7):575-81.

32. Arnautovic K, Arnautovic A. Extramedullary intradural spinal tumors: A review of modern diagnostic and treatment options and a report of a series. Bosn J Basic Med Sci. 2009;9(1):40-5.

33. Kalangu KKN, Dechambenoit G. Essential Practice of Neurosurgery. Nagoya: Access Publishing; 2009. 